during dives, together with a daily supply of clean bedding, reduced the extent of contamination. Only a very restricted range of chemical disinfectants can be used in a pressurised chamber, so not surprisingly contamination could not be completely controlled.

$P$ aeruginosa is a commensal in the bowel and on the skin of a variable number of healthy people and it would be impossible to eliminate all sources of infection among divers. By serotyping the pseudomonads isolated in one dive Alcock found that type II strains accounted for 16 of 18 isolates from the men's ears and 11 out of 12 isolates from the chamber. A single diver with type II in his ears had entered this dive; phage typing showed that all the strains isolated were indistinguishable. In other dives, too, the strains of $P$ aeruginosa isolated belonged to a few serotypes, suggesting that a single diver may often be the source of organisms which spread throughout the chamber complex.

Screening may reduce the chances of divers suffering from acute infection early in the dive, but it has not been effective in reducing the number who eventually harbour Pseudomonas in their ears. The usually recommended prophylactics have given disappointing results. Skin sensitisation and the risk of spreading resistant bacteria are among the dangers associated with topical antibiotics, and drugs such as gentamicin should not be used without clear indications. In practical terms, however, Alcock's study was a success: he had no problems with sensitisation, and resistant strains of $P$ aeruginosa were rarely and briefly found only during an early trial with antibiotic cream. Treated divers rarely suffered from pain in the ears, dives were no longer disrupted, and the operational demands of a highly organised and essential industry were met. ${ }^{1}$ Hoadley, A W, and Knight, D E, Archives of Environmental Health, 1975,
30, 445.

2 Sperati, G, and Pefumo, G, Archivio Italiano di Otologia, Rinologia e Laringologia, 1967, 78, 443.

3 Wright, D N, and Alexander, J M, Archives of Otolaryngology, 1974, 99, 15.

${ }^{4}$ Alcock, S R, Fournal of Hygiene, Cambridge, 1977, 78, 395.

\section{Treatment of depression}

The treatment of depression continues to be a matter of debate, including as it does such diverse remedies as lithium, L-tryptophan, tricyclic antidepressants, monoamine-oxidase inhibitors, and electric convulsion therapy (ECT). A meeting held recently in Glasgow ${ }^{1}$ discussed all these forms of treatment-not only their practical aspects but also the possible biochemical basis of their modes of action.

The results of a recent trial ${ }^{2}$ in Glasgow of antidepressant drugs, given by $\mathrm{R} \mathrm{N}$ Herrington, led to some discussion about the optimum dose of L-tryptophan. This difficulty had arisen because the drug induces the activity of the main degradative enzyme of tryptophan in the liver, tryptophan pyrrolase. ${ }^{3}$ Doses of tryptophan over $4 \mathrm{~g}$ per day might be self-defeating in so far as they resulted in a more rapid degradation of the amino-acid in the liver. Herrington also reported the results of the trial of ECT against L-tryptophan in severe depression, ${ }^{4}$ which had shown the superiority of the former. This report was followed by three other papers dealing with the use of ECT, an emphasis which was appropriate in view of the current controversy surrounding this treatment and the recent memorandum $^{5}$ issued by the Royal College of Psychiatrists. J A G Watt discussed both current medicolegal problems in using ECT and the indications for its use, which included resistance to drug treatment, untoward drug side effects, and severe depression. In view of the wide interest in its efficacy C Freeman's report of a double-blind trial of ECT was especially timely. His control group had had two "dummy ECT" sessions the first week followed by ECT as long as necessary, while the trial group simply received ECT. The results showed that there was no mood improvement after dummy ECT, whereas there was definite marked improvement after the first two genuine shocks. The final outcome was similar in the two groups except that controls took about one week longer (the time that dummy ECT was given) for the improvement to occur.

A R Green described recent studies of the daily administration of rats and mice of an electroconvulsive shock over several days. This produced enhanced behavioural responses to brain 5-hydroxytryptamine (5-HT) and catecholamine receptor stimulation. ${ }^{6-8}$ The failure of subconvulsive shocks to evoke the enhancement and the ability of the convulsant inhalant Indoklon (a drug that has been used ${ }^{9}$ in place of ECT) to produce similar changes suggested that ECT may produce its therapeutic action by a change in monoamine receptor responses.

Dealing with the biochemical aspects of depression, the meeting gave most attention to the part played by $5-\mathrm{HT}$, for which there is now reasonable evidence. Nevertheless, catecholamines also have an important role in depression, ${ }^{10}$ and $\mathrm{D}$ Eccleston discussed the probable interactions of catecholamines and 5-HT, suggesting that in fact the indoleamine $^{11}$ and catecholamine ${ }^{10}$ theories of depression may well be compatible.

While the symposium did not establish clear indications for specific antidepressant treatments, it did give some insight into their relative merits and associated difficulties. It also enabled psychiatrists to hear of some of the experimental approaches now being used to investigate the aetiology of depression.

\footnotetext{
1 Organised by the West of Scotland Postgraduate Education Committee, the Scottish Medical fournal, and Merck Pharmaceuticals.

${ }^{2}$ Herrington, R N, et al, Lancet, 1974, 2, 731.

$3 \mathrm{Knox}, \mathrm{W}$ E, and Auerbach, V H, fournal of Biological Chemistry, 1955, 214, 307.

${ }^{4}$ Herrington, R N, et al, Psychological Medicine, 1976, 6, 673.

5 Royal College of Psychiatrists, British fournal of Psychiatry, 1977, 131, 261.

${ }^{6}$ Evans, J P M, et al, British fournal of Pharmacology, 1967, 56, 193.

Green, A R, Heal, D J, and Grahame-Smith, D G, Psychopharmacology, 1977, 52, 195.

${ }^{8}$ Modigh, K, Fournal of Neural Transmission, 1975, 36, 19.

9 Small, I F, in Psychobiology of Convulsive Therapy, ed M Fink et al, p 65. Washington, DC, Winston, 1974.

${ }^{10}$ Schildkraut, J J, et al, American fournal of Psychiatry, 1967, 124, 600.

11 Van Praag, H, in Neuroregulators and Psychiatric Disorders, ed E Usdin et al, p 163. New York, Oxford University Press, 1977.
}

\section{Dietary calcium}

For over a quarter of a century we have known that the intestinal absorption of calcium can be adapted to changes in dietary intake. ${ }^{1}$ Severe restriction of dietary calcium in man evokes homoeostatic responses from intestine, kidney, and bone. ${ }^{2}$ In experiments on animals calcium deprivation has been shown to lead to osteoporosis as skeletal reserves are mobilised to maintain normocalcaemia. ${ }^{3}$ Clearly, then, estimates of the minimum dietary requirement for calcium 
must be compatible not only with the maintenance of normocalcaemia but also with preservation of the calcium balance. The diet must provide enough calcium for the proportion absorbed to balance obligatory losses.

Some calcium is lost in sweat, ${ }^{4}$ but the major losses occur from the kidney and intestine. Urinary calcium excretion is not a simple linear function of intake, ${ }^{5}$ and even at time of severe dietary restriction $1 \cdot 25-2.5 \mathrm{mmol}$ day (50-100 $\mathrm{mg}$ day) is lost in the urine. ${ }^{6}$ As the serum calcium concentration falls tubular reabsorption increases owing to enhanced parathyroid hormone secretion, ${ }^{8}$ but there is a lower limit to calcium excretion that is not overcome unless frank hypocalcaemia develops. In normal individuals the serum calcium concentration does not fall below $2.25 \mathrm{mmol} 1(9 \mathrm{mg} 100 \mathrm{ml})$ even with severe dietary calcium restriction, because skeletal reserves are mobilised under the influence of parathyroid hormone.

Calcium excretion in the faeces comes from two sources. About $3.25 \mathrm{mmol}$ day (130 $\mathrm{mg}$ day) comes from calcium secreted in the intestinal juices which has escaped reabsorption. ${ }^{9}$ The remainder represents the unabsorbed fraction of dietary calcium. On a dietary intake of 600 to 1000 mg a normal adult absorbs less than half of the ingested calcium and the net absorption varies little over this range. ${ }^{10}$ When calcium intake falls below about $500 \mathrm{mg}$ adaptive mechanisms increase the proportion that is absorbed. ${ }^{1}$ With severe calcium restriction (less than $200 \mathrm{mg}$ day) the efficiency of absorption may rise to $70^{\circ}{ }_{0}-80^{\circ}{ }_{0}$, though net absorption will be diminished. ${ }^{210}$ The increased efficiency of absorption is largely a consequence of increased production of 1,25-dihydroxy vitamin $\mathrm{D}_{3}\left(1,25-(\mathrm{OH})_{2} \mathrm{D}_{3}\right){ }^{11}$ This response is probably mediated through increased secretion of parathyroid hormone, though the hormone does not itself bind to intestine ${ }^{12}$ or increase calcium transport directly ${ }^{13}$ but acts by stimulating renal synthesis of $1,25-(\mathrm{OH})_{2} \mathrm{D}_{3} \cdot{ }^{14}$

The quantitative aspects of these responses are not completely understood. Infusion of parathyroid hormone into dogs to give plasma concentrations only slightly above normal results in hypercalcaemia, owing to increased intestinal and renal calcium transport. ${ }^{15}$ Bone resorption does not appear to contribute to the hypercalcaemic response until much higher rates are used. The level of parathyroid response and the efficiency of intestinal transport at which bone resorption begins to contribute to the maintenance of normocalcaemia in man are not known. Nevertheless, in a recent review of 212 calcium balances in 84 normal subjects Marshall et al found that most were negative at intakes below $600 \mathrm{mg}$ calcium per day. Calcium absorption tends to decrease with age, ${ }^{17}$ and higher intakes may be needed in the elderly. The recommended intake - that which would preserve calcium balance in most of the normal population-may therefore be as high as 900 mg/day. ${ }^{7}$

${ }^{1}$ Nicolaysen, R, Acta Physiologica Scandinavica, 1943, 6, 201.

2 Phang, J M, et al, fournal of Clinical Investigation, 1969, 48, 67.

${ }^{3}$ Harrison, M, and Fraser, R, Fournal of Endocrinology, 1960, 21, 197.

4 Isaksson, B, and Ohlsson, L, Metabolism, 1967, 16, 314.

${ }^{5}$ Peacock, M, Robertson, W G, and Nordin, B E C, Lancet, 1969, 1, 384.

${ }^{6}$ Robertson, W G, and Morgan, D B, Clinica Chimica Acta, 1972, 37, 503.

${ }^{7}$ Marshall, D H, Nordin, B E C, and Speed, R, Proceedings of the Nutrition Society, 1976, 35, 163.

${ }^{8}$ Nordin, B E C, Peacock, M, and Wilkinson, R, in Calcium Parathyroid Hormone and the Calcitonins, eds R V Talmage and P L Munson, p 263. Amsterdam, Excerpta Medica, 1972.

${ }^{9}$ Heaney, R P, and Skillman, T G, fournal of Laboratory and Clinical Medicine, 1964, 64, 29.

10 Wilkinson, $\mathrm{R}$, in Calcium, Phosphate and Magnesium Metabolism, ed B E C Nordin. Edinburgh and London, Churchill Livingstone, 1976.

${ }^{11}$ Boyle, I T, et al, in Endocrinology 1971. Proceedings of the Third International Symposium, ed S Taylor. London, Heinemann, 1972.
12 Neuman, W F, et al, Calcified Tissue Research, 1975, 18, 263.

${ }_{13}$ Garabedian, M, et al, Endocrinology, 1974, 94, 1022.

14 Garabedian, M, et al, Proceedings of the National Academy of Sciences of the United States of America, 1972, 69, 1673.

15 Parsons, J A, and Reit, B, Nature, 1974, 250, 254.

${ }^{16}$ Parsons, J A, Neer, R M, and Potts, J T, jun, Endocrinology, 1971, 89, 735.

17 Bullamore, J R, et al, Lancet, 1970, 2, 535.

\section{Management of abdominal aneurysm}

To operate or not to operate: that is the question posed by aneurysm of the abdominal aorta. Arterial surgery began only in the 1950s, and even now many undergraduates and even postgraduates learn little about its role. Thus many clinicians, particularly the older ones, have neither the knowledge nor the experience to make a decision about the need for surgery, and should refer their patients to a vascular surgeon as soon as possible.

Aneurysm of the abdominal aorta usually affects the section between the renal arteries and the aortic bifurcation; it may be associated with aneurysmal dilatation of the common iliac arteries. The neck of the aneurysm-that short segment of the aorta below the renal arteries-can usually be exposed and clamped without too much difficulty, and replacement of the affected section of artery is now a routine procedure.

Abdominal aneurysms present in three main ways: uncomplicated aneurysm, for which surgery is elective; aneurysm complicated by pressure symptoms giving abdominal or back pain, nausea, or flatulence, and needing early operation; and ruptured aneurysm needing emergency surgery. The mortality rates of the operations vary, as might be expected, with the mode of presentation, and published figures ${ }^{12}$ suggest rates of $2-7 \%, 5-10 \%$, and $50 \%$, for elective, urgent, and emergency surgery respectively.

There is no doubt about the correct procedure in patients with ruptured aneurysm who reach hospital, because without operation they cannot survive. Even though these operations carry a $50 \%$, mortality rate, the survivors' quality of life is sufficiently rewarding to justify operation in nearly every case. ${ }^{3}$ Almost always blood flow can be restored, but subsequent failure of the heart, lungs, and kidneys leads to many deaths, postponed by days of unrewarding intensive care. So the doctor should assess the hazards of operation to the individual patient and sometimes refuse operation on clinical grounds such as extreme age, anuria, or cardiac insufficiency.

The safety of elective surgery for abdominal aneurysm has progressively improved. Hicks et al $^{1}$ reported that the mortality had dropped from $13 \%$ in $1955-65$ to $8.4 \%$ in $1966-73$ and $4 \cdot 2^{\circ}$, in 1971-3. They calculated an aggregated mortality rate of $5.2 \%$ in 12 series, including 1408 elective operations, reported between 1970 and 1975. Thompson et al quote similar figures. This great improvement has occurred despite broadening the criteria for operation. It reflects greater clinical awareness of the condition leading to earlier referral of patients; improved operative and anaesthetic technique, giving a smaller loss of blood and a shorter operating time; improved regulation of fluid balance during and after operation; and the availability of intensive care facilities.

Indeed, surgery and management have reached the stage where overall mortality figures probably exaggerate the risk. At the recent Edinburgh surgical festival J G Pollock reported a $2.9 \%$ mortality rate for 137 elective operations, and no 